\title{
Estimation of the photosynthetic action spectrum: implication for primary production models
}

\author{
Margareth N. Kyewalyanga ${ }^{1,2, *}$, Trevor Platt ${ }^{3}$, Shubha Sathyendranath ${ }^{1,3}$ \\ ${ }^{1}$ Department of Oceanography, Dalhousie University, Halifax, Nova Scotia, Canada B3H 4J1 \\ ${ }^{2}$ Institute of Marine Sciences, University of Dar-es-Salaam, PO Box 668 Zanzibar, Tanzania \\ ${ }^{3}$ Biological Oceanography Division, Bedford Institute of Oceanography, Box 1006, Dartmouth, Nova Scotia, Canada B2Y 4A2
}

\begin{abstract}
A simple method for estimating the photosynthetic action spectrum is developed. The method uses the shape of the absorption spectrum of phytoplankton pigments, scaled to the magnitude of the initial slope of the photosynthesis-light curve as established for broad-band illumination. The method was tested by comparing the estimated action spectra with those measured during a cruise in the North Atlantic, in the fall of 1992. The agreement between the constructed and the measured spectra was good. Both the measured and constructed action spectra were then used to compute daily water-column primary production $\left(P_{Z, T}\right)$ using a spectrally resolved model. The results showed that, at most of the stations, the $P_{Z, T}$ computed using the constructed action spectrum was not significantly different from $P_{Z T}$ calculated using the measured spectrum. Daily water-column primary production was also computed at each station using the average shape of the measured action spectra (spectra averaged over all stations), scaled to the magnitude of broad-band initial slope at that station. The results were similar to the $P_{Z, T}$ values computed using the action spectra constructed for individual stations. The errors that may affect the constructed action spectrum are assessed through a sensitivity analysis The analysis suggests that, for our data, the presence of photosynthetically inactive pigments causes negligible errors in the computed $P_{Z . T}$. An assessment of the effects of random errors in the action spectrum showed that the error in the computed primary production was on average $1.5 \%$ (under the conditions chosen for the computation), when random errors of up to $\pm 20 \%$ were introduced into the action spectrum. However, given similar conditions, systematic errors of similar magnitude in the action spectrum cause an average error of about $6 \%$ in the computed water-column primary production.
\end{abstract}

KEY WORDS: Photosynthesis · Action spectrum - Absorption spectrum - Phytoplankton - Primary production

\section{INTRODUCTION}

Spectral dependencies are often ignored in computations of primary production, even though it is well known that light transmission underwater, light absorption by phytoplankton, and the efficiency of utilization of the absorbed light in photosynthesis are all wavelength-dependent. That is to say, broad-band models are often used, for simplicity and convenience, where spectral ones would be more realistic. This simplification, however, may lead to significant discrepancies when the estimates of primary production are compared with the results of in situ production mea-

·E-mail: maggie@is2.dal.ca surements (Kiefer \& Strickland 1970, Harrison et al. 1985, Sathyendranath et al. 1989, Kyewalyanga et al. 1992). Therefore, it is advisable, where possible, to use spectrally resolved models for computation of primary production.

Among the essential information required for implementation of a spectrally resolved model are $\alpha^{B}$, the initial slope, and $P_{m}^{B}$, the assimilation number, which are both determined from the photosynthesis-irradiance ( $P$ vs $I$ ) curve. The superscript $B$ indicates normalization to phytoplankton biomass $B$. Of these 2 parameters, $\alpha^{B}$ is known to be dependent on wavelength $\lambda$, whereas $P_{m}^{B}$ is usually taken to be wavelength-independent (Pickett \& Myers 1966). The existing methods for directly determining the photosynthetic action 
spectrum, based on ${ }^{14} \mathrm{C}$ fixation (Lewis et al. 1985a, Schofield et al. 1990, 1991, Warnock 1990), are relatively complicated and time-consuming compared with the broad-band measurements of $\alpha^{B}$. Because of this, very little data are available on the action spectra of natural phytoplankton populations. As a consequence, the use of the action spectrum in computing water-column primary production is often limited to an average shape (scaled to the magnitude of the broadband $\alpha^{B}$ ) obtained from a few measurements (e.g. Platt \& Sathyendranath 1988, Sathyendranath et al. 1989, 1995, Platt et al. 1991, Kyewalyanga et al. 1992). The implicit assumption in such computations is that errors in the computed production caused by ignoring possible variations in the shape of the action spectrum are negligible. However, this assumption has not been tested in the field for lack of sufficient data on the photosynthetic action spectra of natural phytoplankton population. The present data set, with 20 measured and 20 constructed action spectra, offered an opportunity for testing the assumption. In this paper, we examine the validity of assuming a constant shape for the action spectrum in computing primary production.

It would also be advantageous to develop techniques for estimating the shape of the photosynthetic action spectrum, so that, if necessary, the restriction of a constant shape could be relaxed in computations of primary production. One possible approach is presented in this study, where the shape of the phytoplankton absorption spectrum and the magnitude of the broad-band $\alpha^{B}$ are used to construct the photosynthetic action spectrum. Here, it is assumed that the shape of the phytoplankton absorption spectrum is similar to that of the corresponding action spectrum, and that the broad-band $\alpha^{B}$ provides an appropriate estimate of the amplitude. Both the absorption spectrum and the broad-band $\alpha^{B}$ are easier to measure than the photosynthetic action spectrum.

However, there are some factors associated with the measurements that, if ignored, have the potential to cause errors in the constructed action spectrum. For example, if the measured phytoplankton absorption spectrum has a contribution from non-photosynthetic pigments such as the degradation products of chlorophyll (phaeopigments) and photoprotective carotenoids (Krinsky 1979, Siefermann-Harms 1987, Johnsen \& Sakshaug 1993, Sosik \& Mitchell 1995), the shape of the constructed action spectrum will be different from the actual one, in the spectral region where nonphotosynthetic pigments absorb light. Similarly, if the estimated broad-band $\alpha^{B}$ (the scaling factor) is subject to errors, the constructed spectrum will also be incorrect.
Here, a method for constructing photosynthetic action spectra is presented, and applied to data from 20 stations across the North Atlantic. The constructed spectra are then compared with the directly measured ones, and we show that the constructed action spectrum is a good estimator of the measured action spectrum. A theoretical study, using absorption spectra of 6 phytoplankton species belonging to 4 phytoplankton groups (diatoms, prymnesiophytes, chlorophytes and cyanophytes), is also conducted to develop an approach for estimating potential errors due to nonphotosynthetic pigments. The approach developed is then extended to the field samples, to quantify the effect of non-photosynthetic pigments on the constructed action spectra when the spectra are used to compute daily water-column primary production, $P_{z . T}$. Next, the errors that could be introduced in the computed water-column primary production because of random or systematic errors on the action spectrum are assessed through a sensitivity analysis. The measured and the constructed action spectra at each station are compared. Then, both the spectra are used to compute daily water-column primary production and the results are discussed.

\section{DATA COLLECTION AND ANALYSIS}

Study area and sampling. Sampling was conducted twice (in the west-east and east-west directions) in the fall of 1992 (19 September to 21 October) along a track across the North Atlantic, between Halifax, Canada, and Cape Ghir, Morocco (Fig. 1). A variety of

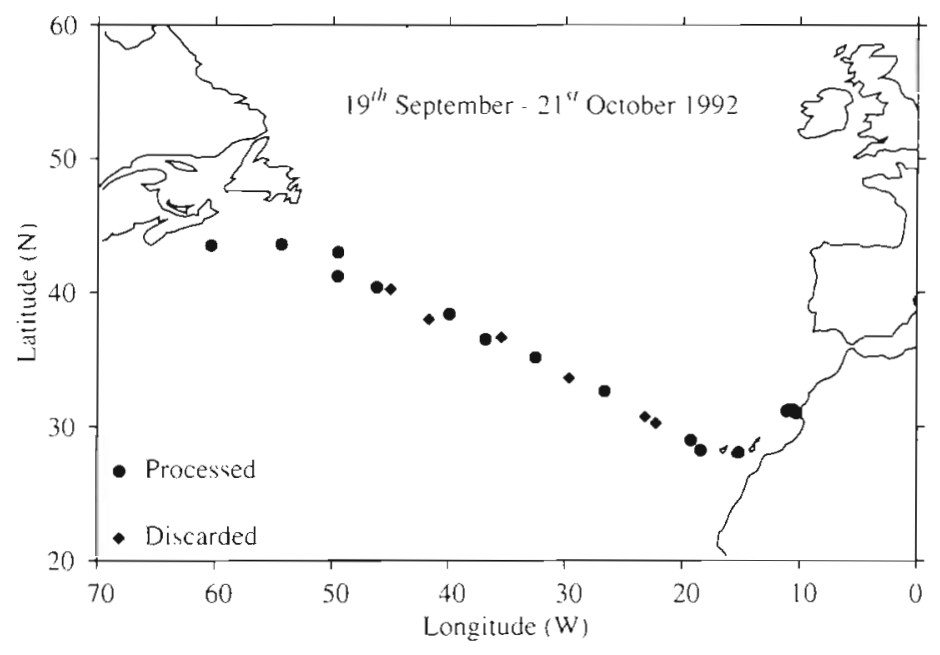

Fig. 1. Locations for 26 stations covered during the fall 1992 cruise from 19 September to 21 October. The track was sampled in the west-east and east-west directions. The final analysis included 20 stations out of 26 . The remaining 6 stations had very low phytoplank-

ton biomass such that the action spectra could not be measured 
hydrographic regimes was encountered along the transect, including the cold continental shelf waters off Nova Scotia, the warm Gulf Stream waters, the oligotrophic subtropical gyre waters, and the upwelling waters off the northwest coast of Africa. After the west-east transect, an $8 \mathrm{~d}$ time series station was occupied in the upwelling waters off the coast of Morocco.

At each station, a sample for the action spectrum was collected from 1 depth using a continuous pump sampler (Herman et al. 1984). The continuous pump was also used to collect samples for broad-band $P$ vs $I$ parameters, absorption spectra and chlorophyll a (chl a) concentrations from 3 depths, including the one from which the water for measuring the action spectrum was collected. Samples for biomass profiles, depthdependent in situ production measurements and nutrient profiles were collected from 11 or more depths in the upper $200 \mathrm{~m}$, using a Niskin-bottle rosette attached to another CTD probe. In total, 26 stations were sampled during the cruise. In the present study, however, only 20 stations are considered; at the remaining 6 stations the biomass was so low that the action spectra could not be measured (Fig. 1).

Phytoplankton absorption spectrum. A water sample (from 0.5 to $1.5 \mathrm{l}$, depending on the biomass concentration) was filtered onto $25 \mathrm{~mm} \mathrm{GF/F} \mathrm{(Whatman)}$ filters using a vacuum filtration pump, at low pressure. The optical density (absorbance) of total particulate materials $D_{t}(\lambda)$ at each wavelength $\lambda_{1}$ with the subscript $t$ indicating total particles, was determined in a spectrophotometer (Beckman DU-64), using the filter technique (Yentsch 1962, Kiefer \& SooHoo 1982, Mitchell \& Kiefer 1984, Kishino et al. 1985, Hoepffner \& Sathyendranath 1992, Cleveland \& Weidemann 1993).

The pigments were extracted from the particles (Kishino et al. 1985) using a mixture of $90 \%$ acetone and dimethyl sulphoxide, as in Hoepffner \& Sathyendranath (1992). The optical density of the residual particles $D_{\mathrm{d}}(\lambda)$ was then measured, and the difference between $D_{\mathrm{t}}(\lambda)$ and $D_{\mathrm{d}}(\lambda)$ gave the phytoplankton absorbance spectrum on the filter, $D_{f}(\lambda)$. The $D_{f}(\lambda)$ spectrum was corrected for the pathlength-amplification factor, as in Hoepffner \& Sathyendranath (1992), to get the optical density of phytoplankton in suspension, $D_{\mathrm{p}}(\lambda)$. The $D_{\mathrm{p}}(\lambda)$ values were then converted to absorption coefficient $\left(\mathrm{m}^{-1}\right), a_{\mathrm{p}}(\lambda)$, as follows:

$$
a_{\mathrm{p}}(\lambda)=\frac{2.3 D_{\mathrm{p}}(\lambda)}{L}
$$

where 2.3 is the conversion factor from decimal logarithms to natural logarithms and $L(m)$ is the pathlength. The phytoplankton absorption spectra were then decomposed into Gaussian bands (Hoepffner \& Sathyendranath 1991, 1993) representing absorption

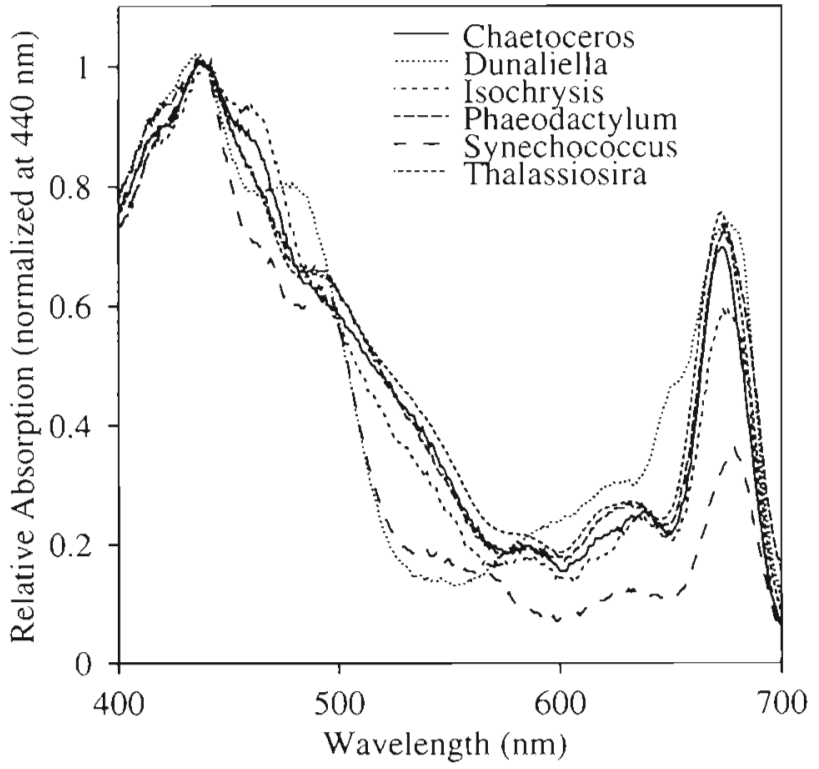

Fig. 2. Shapes of absorption spectra of 6 phytoplankton species used in the sensitivity analysis. Spectra are normalized to 1 at $440 \mathrm{~nm}$, to compare their shapes

by major phytoplankton pigments, i.e. chlorophylls ( $a$, $b$, and $c$ ) and carotenoids. The decomposed absorption spectra were used to study the potential effects on the proposed method of partial absorption by photoprotective carotenoids and phaeopigments in certain spectral regions.

In addition to the field measurements, absorption spectra of 6 phytoplankton cultures-Chaetoceros gracilis (a diatom), Thalassiosira weissflogii (a diatom), Phaeodactylum sp. (a diatom), Dunaliella tertiolecta (a chlorophyte), Isochrysis galbana (a prymnesiophyte), and Synechococcus sp. (a cyanophyte)-were determined using the method outlined above, except that no corrections for detrital materials were made. The cultures were grown at $20^{\circ} \mathrm{C}$, in $f / 2$ medium, under continuous light. With this range of cultures, a variety of shapes of absorption spectra was obtained (see Fig. 2) to study the contribution of non-photosynthetic pigments.

Photosynthetic action spectrum. The action spectrum was measured using a new spectral incubator developed at the Bedford Institute of Oceanography, Dartmouth, Nova Scotia, Canada. Incubation bottles (Corning, $70 \mathrm{mI}$ polystyrene culture flasks) were filled with seawater samples, inoculated with $\mathrm{NaH}^{14} \mathrm{CO}_{3}$ (activity of 0.74 or $1.48 \mathrm{MBq}$ in each bottle, depending on biomass concentrations) and placed in black incubation boxes. Each incubation box, containing 16 light bottles and 1 dark bottle, had a light-tight dark cover, a square glass window $\left(36 \mathrm{~cm}^{2}\right)$ for illumination, and 2 openings for water circulation. The temperature in the 


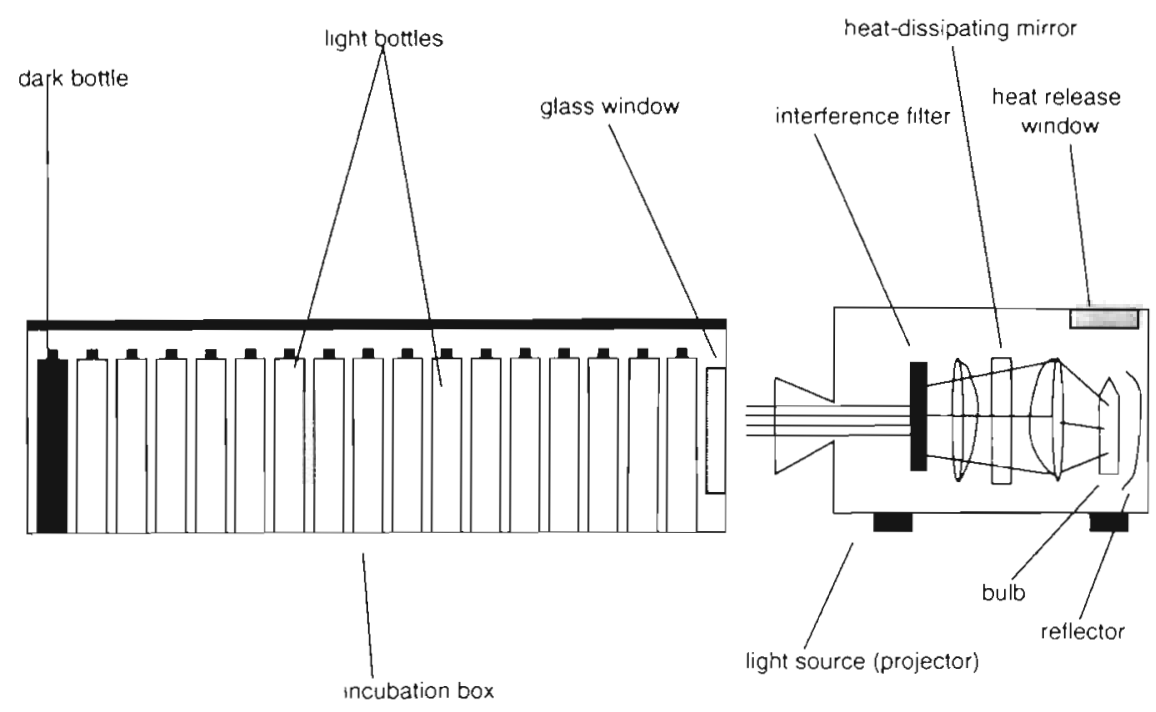

Fig. 3. Illustration of 1 incubation box with its light source, used in the determination of the photosynthetic action spectrum. The box contains 16 light bottles and 1 dark bottle. The bottles are arranged one behind the other to provide a continuous attenuation of the available irradiance. The light source is a slide-projector lamp assembly $(150 \mathrm{~W})$, and the interference (colour) filter is fitted in a slide slot box was maintained, by circulating temperature-controlled water through it, at the temperature of the sampling depth.

The light source for each box was a slide-projector lamp assembly $(150 \mathrm{~W})$. The broad-band light produced by the lamp was screened using an interference filter (Corion, Holliston, MA, USA), which was fitted in the position originally designed for the slide. The projector also had heat mirrors and a fan to dissipate the heat released by the bulb. Inside the box, the bottles were arranged one behind the other to provide a light gradient without the use of neutral density filters (Fig. 3). For each experiment, 12 identical boxes were used, each one illuminated by irradiance of a different wave- band. The 12 bands were chosen to correspond to the maxima of absorption bands of major phytoplankton pigments (Hoepffner \& Sathyendranath 1991) and the wavebands of the satellite sensor, Wide Field-of-view Sensor, SeaWiFS (Hooker et al. 1992). The selected interference filter wavelengths, the SeaWiFS wavebands and the absorption bands of phytoplankton pigments are shown in Table 1.

The samples were incubated for $3 \mathrm{~h}$ and filtered immediately onto GF/F (Whatman) filters, fumed with concentrated hydrochloric acid (for about $5 \mathrm{~min}$ ) to purge unincorporated ${ }^{14} \mathrm{C}$, and counted using a liquid scintillation counter (Beckman LS $5000 \mathrm{CE}$ ). The ${ }^{14} \mathrm{C}$ activity of the dark bottle was subtracted from that of

Table 1 Wavelengths of transmission of the 12 interference filters used in the spectral incubator, and their relation with absorption bands of major phytoplankton pigments [chl $a$, chl $b$, chl $c$, catorenoids (carot.) and phycobilins (phycob.)] and the wavebands of the satellite sensor SeaWiFS. SeaWiFS wavebands are taken from Hooker et al. (1992), and the pigment absorption bands are taken from Neori et al. (1986), Lewis et al. (1986), Hoepffner \& Sathyendranath (1991), and Johnsen et al. (1994a)

\begin{tabular}{|c|c|c|c|c|c|c|c|}
\hline \multicolumn{3}{|c|}{ Interference filters } & \multicolumn{2}{|c|}{ SeaWiFS wavebands } & \multicolumn{3}{|c|}{ Pigment absorption bands } \\
\hline $\begin{array}{c}\text { Center } \\
\text { (nn) }\end{array}$ & $\begin{array}{c}\text { Corion } \\
\text { no }\end{array}$ & $\begin{array}{l}\text { Width } \\
\text { (nm) }\end{array}$ & $\begin{array}{c}\text { Center } \\
(\mathrm{nm})\end{array}$ & $\begin{array}{l}\text { Width } \\
\text { (nm) }\end{array}$ & Pigment & $\begin{array}{c}\text { Center } \\
\text { (nm) }\end{array}$ & $\begin{array}{l}\text { Halfwidth } \\
\text { (nm) }\end{array}$ \\
\hline 415 & $204 \mathrm{~A}$ & 10 & 412 & 20 & Chl a & $410-415$ & $19-24$ \\
\hline 440 & P906 & 10 & 443 & 20 & Chl a & $433-436$ & $29-37$ \\
\hline 460 & $\mathrm{~S} 264$ & 10 & - & - & $\mathrm{Chl} C$ & $459-462$ & $26-39$ \\
\hline 460 & $\mathrm{~S} 264$ & 10 & - & - & Chl $b$ & $463-466$ & $36-45$ \\
\hline 490 & P706 & 10 & 490 & 20 & Carot. & $487-491$ & $41-54$ \\
\hline 490 & P706 & 10 & & & Phycob. & $490-500$ & \\
\hline 510 & U051 & 10 & 510 & 20 & Phycob. & $500-520$ & \\
\hline 532 & $X 721$ & 10 & - & - & Carot. & $529-536$ & $45-54$ \\
\hline 550 & $\mathrm{X} 489$ & 25 & 55.5 & 20 & Phycob. & $540-565$ & \\
\hline 580 & V900 & 10 & - & - & Chl c & $579-586$ & $43-54$ \\
\hline 600 & & 25 & - & - & - & - & \\
\hline 630 & U607 & 10 & - & - & Chl c & $625-645$ & \\
\hline 650 & $697 \mathrm{~A}$ & 25 & - & - & Chl $b$ & $640-654$ & $21-37$ \\
\hline 670 & $409 \mathrm{~A}$ & 10 & 670 & 20 & Chl a & $674-678$ & $20-28$ \\
\hline
\end{tabular}



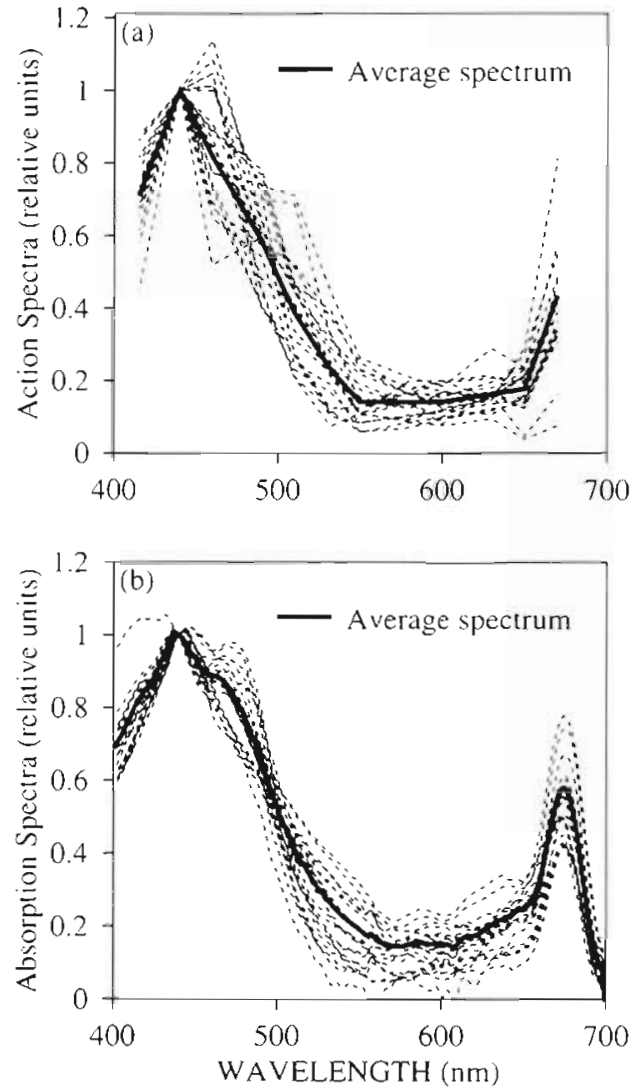

Fig. 4. Shapes of measured spectra for all the 20 stations sampled during the cruise. Spectra are normalized to 1 at $440 \mathrm{~nm}$. to compare the shapes: (a) action spectra, (b) absorption spectra. In both cases, the thick lines represent the average spectrum (of the 20 spectra)

the light bottles, and the carbon fixed was calculated according to Strickland \& Parsons (1972). Production $P$ ( $\mathrm{mg} \mathrm{C} \mathrm{m}^{-3} \mathrm{~h}^{-1}$ ) was then normalized to biomass $B$ (mg chl $\left.\mathrm{a} \mathrm{m}^{-3}\right)$ to yield biomass-specific production, $P^{\beta}(\mathrm{mg}$ C $\mathrm{mg}^{-1}$ chl $a \mathrm{~h}^{-1}$ ).

The irradiance $I\left(\mu \mathrm{mol} \mathrm{m} \mathrm{m}^{-2} \mathrm{~s}^{-1}\right.$ ) reaching the bottles was measured using a $4 \pi$-collector light meter (Biospherical Instruments), by inserting the sensor into each bottle. The initial slope of the $P^{B}$ vs $I$ curve for a wavelength $\lambda, \alpha^{B}(\lambda)\left[\mathrm{mg} C \mathrm{mg}^{-1} \mathrm{chl} a \mathrm{~h}^{-1}\left(\mu \mathrm{mol} \mathrm{m} \mathrm{m}^{-2} \mathrm{~s}^{-1}\right)^{-1}\right]$, was determined by linear regression of $P^{B}$ on $I$ (incident quanta) for each incubation waveband. Since we were interested in the linear part of the $P^{B}$ vs $I$ curve, the data points tending to saturation and any outliers were detected and omitted at the $1 \%$ significance level (Snedecor \& Cochran 1989). Linear regression results were excellent, for all bands and stations, giving coefficients of determination $r^{2} \geq 0.96$. A plot of $\alpha^{\beta}(\lambda)$ as a function of $\lambda$ gave the photosynthetic action spectrum.

There was considerable variation in the shape of the measured action spectra from the different stations (see Fig. 4a). The absorption spectra corresponding to the action spectra are also shown in Fig. 4 b, after normalization to 1 at $440 \mathrm{~nm}$.

Broad-band photosynthesis-light parameters. Broadband $P$ vs $I$ experiments were conducted by incubating phytoplankton samples for $3 \mathrm{~h}$ onboard the ship. according to the procedure described in Irwin et al. (1990) The equation of Platt et al. (1980) was fitted to the $P^{B}$ vs $I$ data, to give the photosynthetic parameters

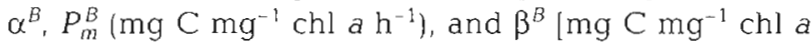
$\left.\mathrm{h}^{-1}\left(\mu \mathrm{mol} \mathrm{m} \mathrm{m}^{-2} \mathrm{~s}^{-1}\right)^{-1}\right)$. The parameter $P_{m}^{B}$ gives the value of $P^{B}$ at saturating irradiance, and $\beta^{B}$ is the negative slope of the $P^{B}$ vs $I$ curve at photo-inhibiting light levels.

The broad-band $\alpha^{B}$ estimated in this way was corrected for the bias due to the spectral quality of the incident irradiance. The emission spectrum of the tungsten-halogen lamp used in the incubator was not neutral; the spectral quality of the light could be further modified through absorption by water samples and by the walls of incubation bottles. To assess the change in spectral quality of the incident light from the first to the last bottle in the incubation box (pathlength of $0.27 \mathrm{~m}$ ), the spectrum of the light incident on the last bottle was estimated using an exponential decay function, in which the exponent was set to the product of the measured absorption coefficient of a sample bottle filled with water $\left(\mathrm{m}^{-1}\right)$ and the pathlength $(\mathrm{m})$. The resulting spectrum was not significantly different from the spectrum of the light incident on the first bottle (Fig. 5), suggesting that the deviation of the spectrum from its original shape, as it passed through the samples, was negligible and could be ignored. For a comparable pathlength $(0.3 \mathrm{~m})$, but with a different type of lamp, Babin et al. (1994) calculated the error in the computed light absorption, which might be incurred by assuming a constant irradiance spectrum, and also found it to be negligible. Therefore, the broad-band $\alpha^{B}$ was corrected only for the spectral quality of the light from the tungstenhalogen lamp.

The tungsten-halogen lamp spectrum has a minimum in the blue and increases (quasi-linearly) to a maximum in the red part of the spectrum (Kingslake 1965; see also Fig. 5). This implies that the light absorbed by the water sample will be different from what would be absorbed by the same sample if the incident light were spectrally neutral. To correct for this bias, we used the ratio ( $X$, dimensionless) of the unweighted, spectral-mean absorption of phytoplankton to the mean absorption coefficient weighted by the shape of the emission spectrum of the tungsten-halogen lamp. The spectral, unweighted mean absorption coefficient of phytoplankton in the sample, $\bar{a}_{p}$, was given by. 


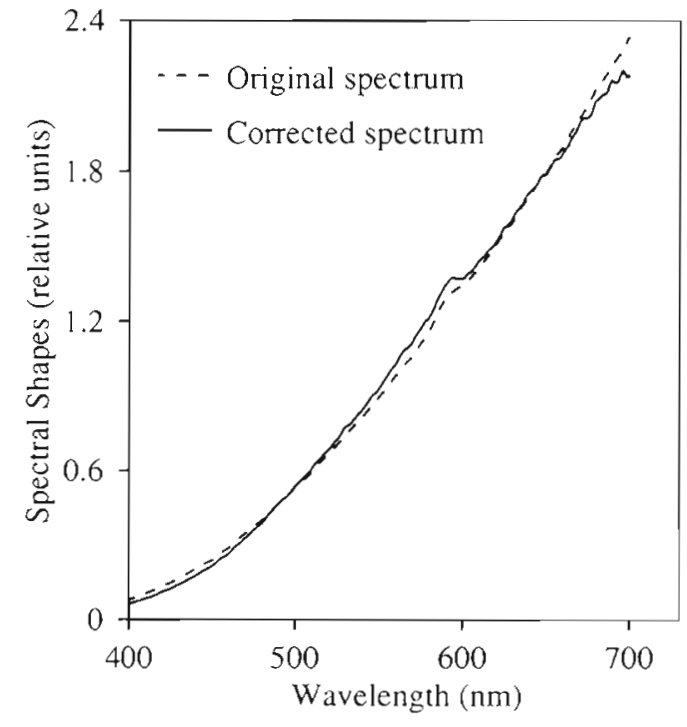

Fig. 5. Tungsten-halogen lamp spectra, normalized to their mean value to define the shape. The dashed line indicates the original shape of the spectrum, the solid line shows the spectral shape of the irradiance reaching the last bottle in the incubator. The label 'corrected' is used to indicate that absorption by the water samples and the bottle walls is accounted for

$$
\bar{a}_{p}=\frac{\int_{400}^{700} a_{p}(\lambda) \mathrm{d} \lambda}{\int_{400}^{700} \mathrm{~d} \lambda}
$$

where $a_{p}(\lambda)$ is the phytoplankton absorption coefficient at $\lambda$. The weighted mean absorption $\bar{a}_{T}$ that accounts for the spectral quality of the tungsten-halogen spectrum was computed as:

$$
\bar{a}_{\mathrm{T}}=\frac{\int_{400}^{700} a_{\mathrm{p}}(\lambda) I_{\mathrm{T}}(\lambda) \mathrm{d} \lambda}{\int_{400}^{700} I_{\mathrm{T}}(\lambda) \mathrm{d} \lambda}
$$

where $I_{T}(\lambda)$ is the incident (tungsten-halogen lamp) irradiance in the incubator at $\lambda$ (subscript $T$ on $a$ and $I$ refers to the tungsten-halogen spectrum).

The correction factor, the ratio $X$, is then given by:

$$
X=\frac{\bar{a}_{p}}{\bar{a}_{T}}
$$

This kind of correction for the spectral quality of the incubation lamp has been applied by other workers (for example, Dubinsky et al. 1986, Cleveland et al. 1989, Schofield et al. 1991, Babin et al. 1995).

The calculated value of $X$ ranged from 1.2 to 1.8 , for the entire data set, showing that the mean absorption weighted by the tungsten-halogen spectrum was much lower than the unweighted mean. To test whether the use of this correction factor is justified, we first examined the linear regression of uncorrected broad-band (a) Uncorrected Broad-band $\alpha^{B}$

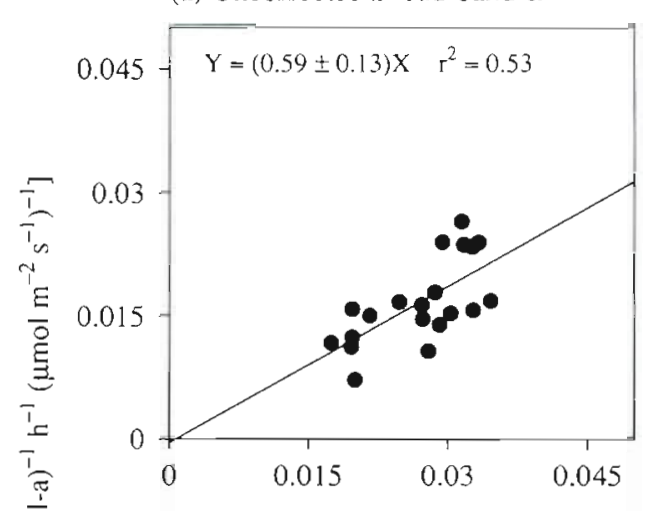

(b) Corrected Broad-band $\alpha^{B}$

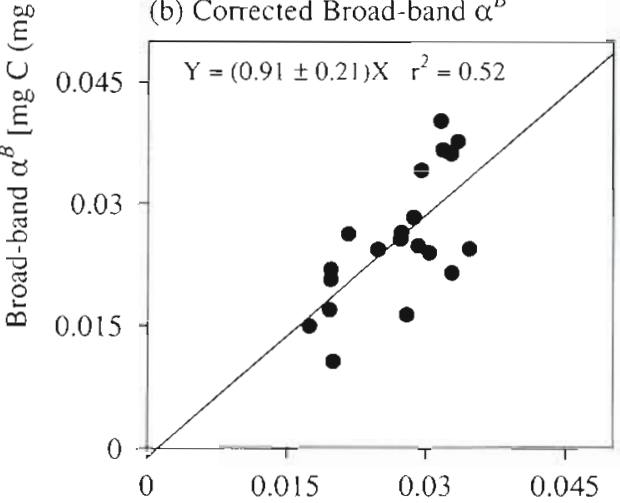

Mean $\alpha^{B}(\lambda)\left[\operatorname{mg} C(\operatorname{mgchl}-\alpha)^{-1} h^{-1}\left(\mu \mathrm{mol} \mathrm{m} \mathrm{m}^{-2} \mathrm{~s}^{-1}\right)^{-1}\right]$

Fig. 6. Linear regression analyses of broact-band $\alpha^{B}$ on spectral average of $\alpha^{B}(\lambda)$ for 20 stations sampled during the 1992 cruise. (a) Originally measured $\alpha^{B}$, not corrected for any bias, with regression equation: $Y=(0.59 \pm 0.13) X\left(n=20, r^{2}=0.53\right)$. In this case, the slope is significantly different from 1.0 at the $5 \%$ level. (b) Measured $\alpha^{B}$, corrected for the bias introduced by the tungsten-halogen lamp spectrum: $Y=(0.91 \pm 0.21) X$ $\left(n=20, r^{2}=0.52\right)$, the slope is not significantly different from 1.0. Regression lines pass through the origin. Low $\mathrm{r}^{2}$, indicating high scatter along the regression line, is caused by pooling 20 different stations

$\alpha^{B}$ on the spectral mean of $\alpha^{B}(\lambda)$, and found the slope to be $0.59 \pm 0.13$ (SE) (Fig. 6a), significantly different from 1.0 at the $5 \%$ level (Student's $t$-test, $\mathrm{n}=20$ ). When the same regression was repeated using the corrected $\alpha^{B}$ values (Fig. 6b), the slope became $0.91 \pm 0.21$, not significantly different from $1.0(n=20)$. Therefore, each measured broad-band $\alpha^{B}$ was multiplied by its corresponding $X$, to correct for the bias introduced by the shape of the spectrum of the tungsten-halogen lamp. The corrected broad-band $\alpha^{B}$, for all stations and depths sampled $(n=60)$, varied by a factor of about 11

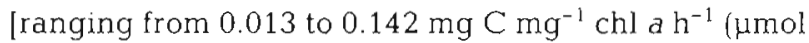
$\left.\mathrm{m}^{-2} \mathrm{~s}^{-1}\right)^{-1}$; and the corresponding $P_{m}^{B}$ (ranging from

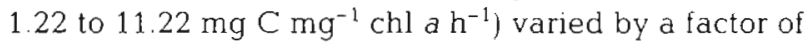
about 9 . 
In situ production. In situ production was measured at 7 stations, at the time series location. Water samples were collected from 11 depths between the surface and $100 \mathrm{~m}$. Incubations were made as explained in Irwin et al. (1990). Daily primary production at each depth ( $\mathrm{mg} \mathrm{C} \mathrm{m} \mathrm{m}^{-3} \mathrm{~d}^{-1}$ ) was calculated as in Strickland \& Parsons (1972), and the integrated water-column primary production, $P_{Z, T}\left(\mathrm{mg} \mathrm{C} \mathrm{m}^{-2} \mathrm{~d}^{-1}\right)$, was computed using the trapezoid rule (Britton 1956). The in situ $P_{Z, T}$ ranged from 1.0 to $2.45 \mathrm{~g} \mathrm{C} \mathrm{m}^{-2} \mathrm{~d}^{-1}$.

Biomass concentration and profiles. Water samples for chl a measurements (3 replicate $100 \mathrm{ml}$ samples) were filtered onto GF/F filters, then extracted in the dark using $90 \%$ acetone for $24 \mathrm{~h}$ at $0^{\circ} \mathrm{C}$. Chl a concentration was determined fluorometrically by the method of Yentsch \& Menzel (1963) as modified by HolmHansen et al. (1965). For determining the biomass profile, chl a concentration was measured at 17 depths between the surface and $200 \mathrm{~m}$. The biomass profile $B(z)$, where $z$ is the depth, was then fitted to a shiftedGaussian function (Platt et al. 1988):

$$
B(z)=B_{0}+h /(\sigma \sqrt{2 \pi}) \exp \left(-\left(z-z_{m}\right)^{2} / 2 \sigma^{2}\right)
$$

where $B_{0}$ is the background pigment concentration ( $\mathrm{mg} \mathrm{chl} \mathrm{a} \mathrm{m}{ }^{-3}$ ); $h$ is the total chl a concentration within the peak $\left(\mathrm{mg} \mathrm{m}^{-2}\right) ; \sigma$ is the standard deviation around the peak value $(m)$ and $z_{m}$ is the depth of chl a maximum $(m)$. These 4 parameters were used to generate the chl a concentration at each depth for the computation of water-column primary production.

Construction of the action spectrum. Spectrally resolved primary production models that are based on available light require the action spectrum as one of the inputs. To measure the action spectrum using the ${ }^{14} \mathrm{C}$ method, the samples have to be incubated at a range of irradiance levels for a series of wavelengths to get initial slopes of $P^{B}$ vs $I$ curves as a function of wavelength. Methods for such direct determination of the action spectrum exist. Lewis et al. (1985a) developed a method for measuring the photosynthetic action spectrum by incubating $1 \mathrm{ml}$ samples in light of different wavelengths and magnitudes. Schofield et al. (1990) modified the method by including background light to account for the Emerson enhancement effect (Emerson 1957, see also Schofield et al. 1991, 1996).

Regardless of the method used, direct measurement of the photosynthetic action spectrum is expensive, complicated and labour-intensive, relative to broadband $\alpha^{B}$ measurements. These limitations discourage routine determinations of the action spectrum at sea. As a consequence, only a few measurements have been made, mostly in the North Atlantic (e.g. Lewis et al. 1985a, b, 1988, Kyewalyanga et al. 1992) and some in the Southern California Bight (e.g. Schofield et al. 1991). Therefore, there is a need to develop simple and economical methods for determining the photosynthetic action spectrum.

In the present study, we explore the use of the shape of the phytoplankton absorption spectrum, and the magnitude of the broad-band $\alpha^{B}$ to construct the photosynthetic action spectrum. The main assumption underlying the method is that the shape of the action spectrum is similar to that of the phytoplankton absorption spectrum for a given water sample. For such an assumption to be valid, the effect of nonphotosynthetic pigments on the shape of phytoplankton absorption and on the light energy transfer efficiency would have to be negligible. The validity of this assumption is discussed in the section dealing with non-photosynthetic pigments. The amplitude of the constructed action spectrum was determined from the magnitude of the broad-band $\alpha^{B}$ measured on the same sample, corrected for the spectral quality of the irradiance generated by the tungsten-halogen lamp. Thus, the action spectrum $\alpha_{c}^{B}(\lambda)$, with the subscript $c$ indicating 'constructed', was estimated as:

$$
\alpha_{c}^{B}(\lambda)=\frac{\alpha^{B} \times a_{p}(\lambda)}{\bar{a}_{p}}
$$

\section{RESULTS}

\section{Comparison of constructed and measured action spectra}

The shape of the action spectrum (and that of the absorption spectrum) varies from one station to another (Fig. 4). However, there is a good agreement between the shapes of the constructed and the measured action spectra at each station, for all the stations sampled (see Fig. 7 for an example). When the constructed $\alpha^{B}(\lambda)$ are plotted against the measured values (Fig. 7c), a slope of 1.0 would imply perfect agreement between amplitudes, and a high coefficient of determination $\left(\mathrm{r}^{2}\right)$ that the shapes of the spectra were well matched. A slope of less than 1.0 would show that the constructed spectrum had a lower amplitude compared with the measured one, and vice versa.

Out of the 20 stations, the slopes of 15 stations $(75 \%$ of the data) were found to be not significantly different from 1.0 at the $1 \%$ significance level (Student's $t$-test): the slopes of 4 stations were found to be significantly lower than 1.0, and only 1 station had a slope significantly higher than 1.0. The 4 stations that had slopes significantly less than 1.0 (see Fig. 8 for an example) were located in coastal waters, 2 from the eastern and the other 2 from the western North Atlantic. These stations had low broad-band $\alpha^{B}$, leading to low amplitudes of the constructed action spectra relative to the 


\section{Station 4: $21^{5 /}$ SEPTEMBER. 1992}

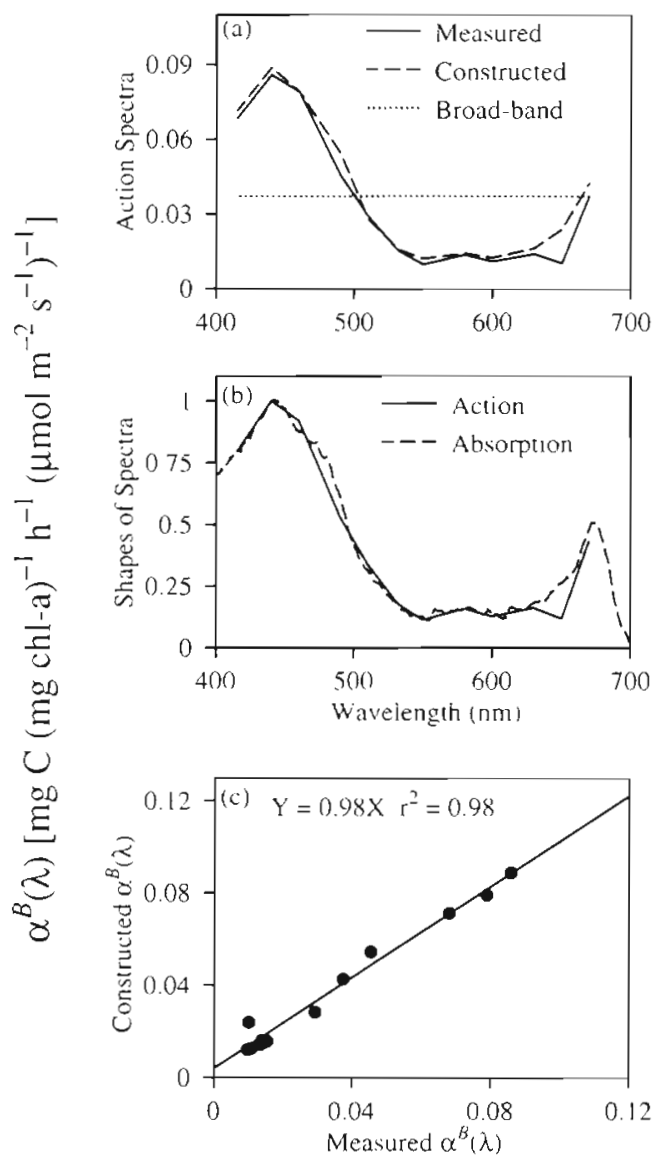

Fig. 7 Example of the comparison of measured and constructed action spectra (Stn 4, depth $80 \mathrm{~m}$, sampled on 21 September 1992): (a) amplitudes and (b) shapes; spectra are normalized to their mean values. (c) Linear regression: slope of $0.986\left(r^{2}=0.98, n=12\right)$ is not significantly different from 1.0 at the $1 \%$ level

measured ones. This mismatch in the amplitudes could have been caused by measurement errors. None of the intercepts was significantly different from zero. On average, $93 \%$ of the variance in the shape of the measured action spectrum could be explained by the shape of the constructed action spectrum.

In the next section we analyse various factors that could affect the constructed action spectrum, and assess the magnitude of errors caused by such factors, in the computed water-column primary production.

\section{Effect of non-photosynthetic pigments on the shape of the constructed action spectrum}

The comparison of measured and constructed action spectra revealed some differences, though small, in the shapes of the spectra. In most cases, the mismatch in
Station 17: $4^{\text {th }}$ OCTOBER, 1992

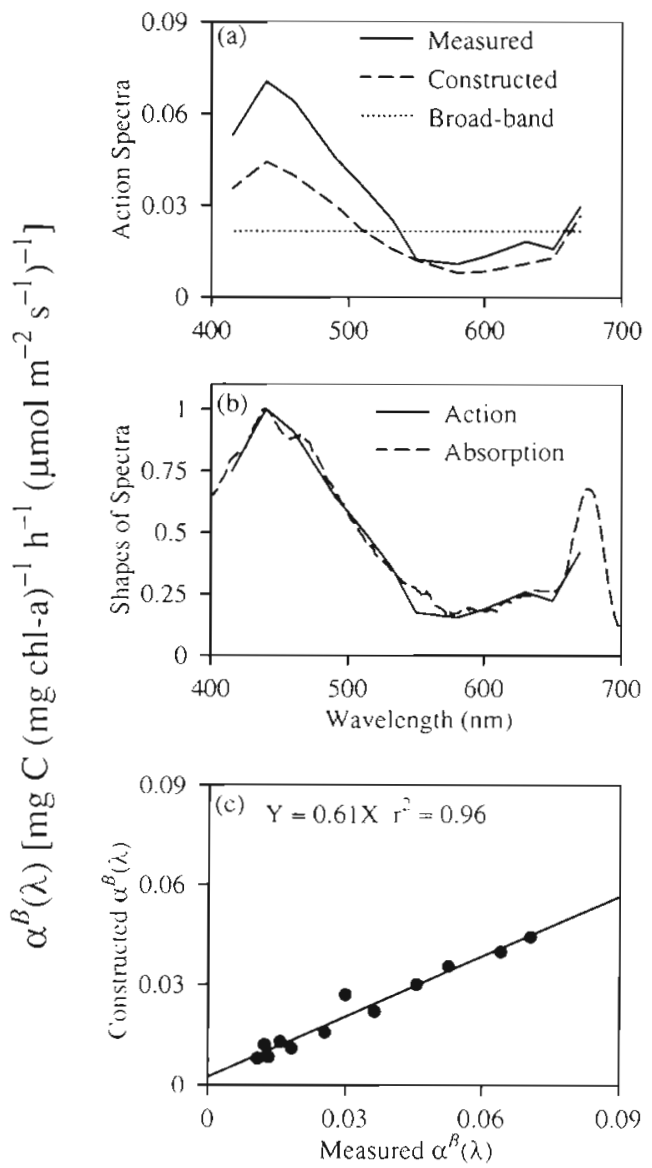

Fig. 8. As in Fig. 7 but for a station occupied on 4 October 1992. This is an example of when the slope of the regression line $0.61\left(r^{2}=0.96 ; n=12\right)$ was significantly lower than 1.0 at the $1 \%$ level

the shapes occurred near 415 and $490 \mathrm{~nm}$. If we assume for the moment that the shape of the measured action spectrum is perfect, that is, with no measurement errors, then a possible source of the difference in shapes between the measured and constructed spectra may be the presence of photosynthetically inactive pigments, which absorb light but do not transfer the energy to the reaction centers for use in photosynthesis. The commonly known, non-photosynthetic pigments are photoprotective carotenoids. The degradation products of chl a do not transfer excitation energy to reaction centers; therefore, they will also be regarded as non-photosynthetic pigments in this context.

It is known that phaeopigments have their blue absorption maximum near 409 to $415 \mathrm{~nm}$ (Zscheile \& Comar 1941, Vernon 1960, Johnsen \& Sakshaug 1993), whereas photoprotective pigments, such as zeaxanthin, diatoxanthin and diadinoxanthin (SiefermannHarms 1987, Bidigare et al. 1989, Demers et al. 1991, 
Demmig-Adams \& Adams 1992, Johnsen et al. 1994b), absorb in the same region as photosynthetic carotenoids, i.e. between 400 and $550 \mathrm{~nm}$. Hoepffner \& Sathyendranath $(1991,1993)$ decomposed the absorption spectrum of phytoplankton pigments into 13 Gaussian bands representing absorption by chlorophylls and carotenoids. Two of the bands had peaks centered nominally at $415 \mathrm{~nm}$ and $490 \mathrm{~nm}$. We adopt these 2 bands as our target bands to study the potential effects of absorption by phaeopigments (absorption peak at $415 \mathrm{~nm}$ ) and photoprotective carotenoids (with absorption peak at $490 \mathrm{~nm}$.

One of the approaches that could be used to assess the effect of non-photosynthetic pigments is the comparison of measured and constructed action spectra at the target wavelengths. The measured action spectrum is affected only by photosynthetically active pigments, whereas the constructed one, being derived from the absorption spectrum, is influenced by both photosynthetic and non-photosynthetic pigments. Therefore, the ratio of the measured $\alpha^{B}(\lambda)$ to the constructed $\alpha_{c}^{B}(\lambda)$, at a target Gaussian peak wavelength $\lambda$, would give the fractional absorption $F$ (cf. Johnsen et al. 1994b) by photosynthetically active pigments within that particular Gaussian band:

$$
F=\frac{\alpha^{B}(\lambda)}{\alpha_{c}^{B}(\lambda)}
$$

Then, the fraction of absorption by non-photosynthetic pigments would be $(1-F)$. This fraction $(1-F)$ could be subtracted from the amplitude of the corresponding band and the process repeated for each of the target Gaussian bands. Next, the Gaussian bands corrected in this way could be used to reconstruct an absorption spectrum free of the effects of non-photosynthetic pigments. Finally, the shape of the corrected absorption spectrum could be used to construct the action spectrum.

This proposed correction for non-photosynthetic pigments was tested under idealized conditions, using simulated action spectra of 6 phytoplankton species (cultures). To simulate the action spectra, we began by decomposing the absorption spectra of the 6 cultures into Gaussian absorption bands. We then generated absorption spectra of photosynthetic pigments, by assuming that $50 \%$ (an extreme case) of the absorption at the 2 target bands was due to non-photosynthetic pigments. This 'photosynthetic absorption spectrum' was used to create the action spectrum, assuming a wavelength-independent quantum yield. The correction procedure outlined above was tested on these 6 pairs of absorption and action spectra, and it was seen that, at least under these ideal simulated conditions, the proposed procedure, of retrieving the action spectrum from the shape of the absorption spectrum and the broad-band $\alpha^{B}$, worked well for the absorption spectra of the 6 species chosen for the analysis (Fig. 2).

We next calculated $F$ and $(1-F)$ fractions at the 2 peak wavelengths for our field samples and used them to correct the absorption spectra, and then used the shape of the corrected absorption spectra to construct the action spectra free of non-photosynthetic pigments. The calculated fractions of non-photosynthetic pigments at the 2 target wavelengths ( 415 and $490 \mathrm{~nm}$ ) ranged from 0 to $28 \%$ and 0 to $39 \%$, respectively. However, at most of the stations, the contribution of non-photosynthetic pigments at the target bands was low (below 10\%), suggesting that these pigments did not have a large influence on the shapes of the measured absorption spectra. Then, to evaluate the impact of this correction on water-column production, the constructed (corrected) action spectrum was used to compute primary production at each station with a spectrally resolved model (Sathyendranath \& Platt 1989), according to which, production $P(z)$ at depth $z$ is given by:

$$
P(z)=\frac{B(z) \Pi(z)}{\sqrt{1+\left[\Pi(z) / P_{m}^{B}(z)\right]^{2}}}
$$

where, $B(z)$ is the biomass at depth $z$, and $\Pi(z)$ is given by:

$$
\Pi(z)=\sec \theta \int_{400}^{700} \alpha^{B}(\lambda) I_{\mathrm{d}}(z, \lambda, \theta) \mathrm{d} \lambda+1.20 \int_{400}^{700} \alpha^{B}(\lambda) I_{\mathrm{s}}(z, \lambda) \mathrm{d} \lambda
$$

where $I_{\mathrm{d}}$ and $I_{\mathrm{s}}$ are the direct and diffuse components of the available light, as computed in Sathyendranath \& Platt (1988), $\theta$ is the sun zenith angle in water and 1.20 is the inverse of the mean cosine for perfectly diffuse skylight after refraction at a flat sea surface.

First, the depth at which the irradiance reached $0.01 \%$ of the surface irradiance was determined for each station. This depth was assumed to be the photic depth (it ranged from 52 to $130 \mathrm{~m}$ for the 20 stations processed). Next, the water column from the surface to the photic depth was partitioned into 250 layers. Therefore, the depth interval varied from station to station, depending on the photic depth. The shape and amplitude of the action spectrum were assumed to be the same throughout the water-column. However, the magnitude of $P_{m}^{B}$ and the total particulate absorption spectrum (for computation of underwater light transmission) were allowed to vary between the mixed layer and the deep layer. The mixed-layer depth was defined as the depth at which the temperature change between the surface and that depth was $\geq 0.1^{\circ} \mathrm{C}$.

Values of $P_{m}^{B}$ and particulate absorption (required for computation of spectral light transmission underwater) in the 2 layers were assigned based on the broad-band incubations of samples and the measured total particulate absorption spectra from 3 depths at each station. If 
1 depth was sampled for $P^{B}$ vs I parameters and particulate absorption in the mixed layer or the deep layer, its value was used throughout that layer. If 2 depths were sampled in either of the layers, the parameters or spectra were averaged and the averages were used in the layer. If all 3 depths sampled were situated in the mixed layer, then the average of the 3 measurements was used for the entire water column. Other inputs such as the biomass distribution and the available irradiance were computed for each of the 250 layers of the photic zone.

Using the trapezoid rule, the computed $P(z)$ values were integrated from the surface to the photic depth to give water-column production, which was then integrated over the daylength (at time intervals of $30 \mathrm{~min}$ ) to give daily water-column primary production at each station $P_{Z, T}\left(\mathrm{~g} \mathrm{C} \mathrm{m}^{-2} \mathrm{~d}^{-1}\right)$.

The calculation was then repeated using the constructed (uncorrected) action spectrum. The $2 P_{Z, T}$ values (at each station) were compared, and the maximum relative difference was only $2.3 \%$ (see Fig. 9). This indicates that, at least for the data discussed here, the effects of the degradation products of chl $a$ and that of the photoprotective carotenoids on the constructed shapes of the action spectra had negligible consequences for computed water-column production.

The procedure we applied of comparing the shapes of measured and constructed action spectra is one of the ways to quantify the effect of non-photosynthetic pigments. It was possible to apply the procedure to our field samples because the measured action spectra were available. Otherwise, an independent estimate of the pigments would have to be made (Jeffrey 1981, Mantoura \& Llewellyn 1983, Bidigare et al. 1989, Sakshaug et al. 1991, Head \& Horne 1993, Johnsen et al. $1994 \mathrm{~b})$, and we would need information on the in vivo specific absorption coefficients for these pigments.

Other approaches to determine action or absorption spectra free of non-photosynthetic pigments have been proposed (Neori et al. 1986, Bidigare et al. 1987, Sakshaug et al. 1991, Johnsen et al. 1994b, Sosik \& Mitchell 1995). Bidigare et al. $(1987,1989)$ used a spectral reconstruction method, in which the absorption spectrum is reconstructed from in vivo absorption coefficients of the individual pigments and their respective concentrations. This method requires prior knowledge of major phytoplankton pigments present in the sample and their in vitro absorption spectra, which have to be wavelength-shifted to match their in vivo counterparts before the reconstruction process. Note that, to be able to incorporate the flattening effect of particles in suspension (Duysens 1956), additional information on the size distribution of particles would also be required.

Another approach is to use the in vivo fluorescence excitation spectrum, because it is influenced only by

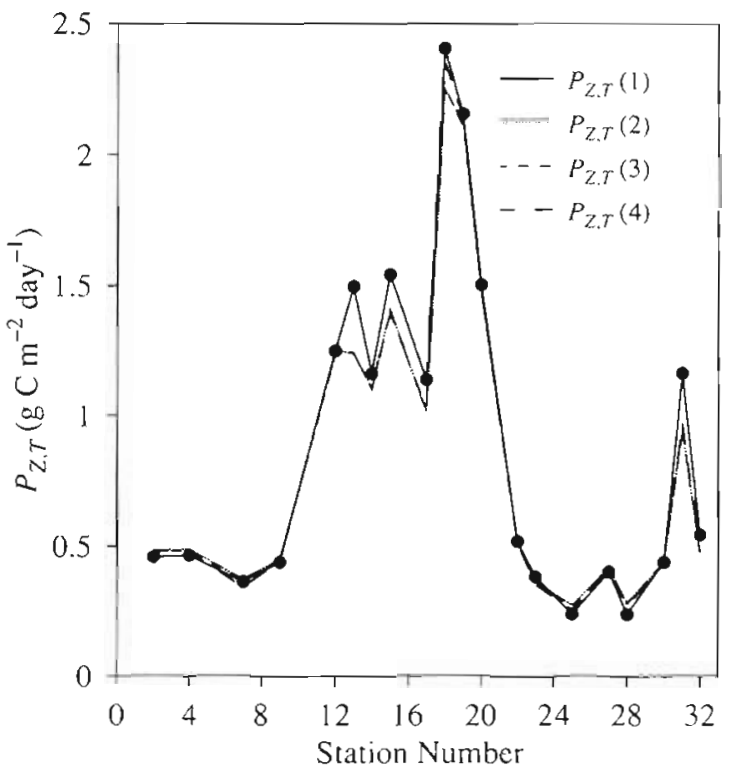

Fig. 9. Daily water-column primary production at each of the 20 stations, computed using different action spectra: $(\bullet) P_{Z, T}\{1\}$, the measured action spectra; $P_{Z, T}(2)$, constructed action spectra, not corrected for non-photosynthetic pigments; $P_{Z, T}(3)$, constructed action spectra, corrected for non-photosynthetic pigments; and $P_{Z, r}(4)$, a constant shape (an average of the 20 measured action spectra), scaled to broad-band $\alpha^{B}$ values

photosynthetically active pigments. Neori et al. (1986, 1988) showred that the shape of the chl a excitation spectrum is a good proxy for the photosystem (PS) II $\mathrm{O}_{2}$-evolution action spectrum. The in vivo fluorescence excitation spectrum was also used by Sakshaug et al. (1991) (see also Johnsen et al. 1992, Johnsen \& Sakshaug 1993), and by Sosik \& Mitchell (1995) who showed a significant difference between the absorption spectrum of total phytoplankton pigments and that of photosynthetically active pigments. Our results do not necessarily contradict the findings of Sosik \& Mitchell (1995), since our results apply only to a particular region and time of year. Regional and seasonal effects depend on the phytoplankton populations present, their light history, and physiological state, which could influence the amount and type of non-photosynthetic pigments present.

\section{Effect of random and systematic errors on the constructed action spectrum}

Having assessed the effect of non-photosynthetic pigments on the shape of the constructed action spectrum, we now assess the effects of random and systematic errors in estimating the action spectrum, on the computed water-column primary production. A simulated 12-point action spectrum (simulated from the 
absorption spectrum of Chaetoceros gracilis grown in cultures) was chosen as the reference (error-free) for this analysis.

\section{Sensitivity analysis of random errors}

Given the Chaetoceros gracilis action spectrum as a reference, a random-number generator was used to create errors that were less than or equal to $\pm 20 \%$ of the reference values. Each of these numbers was then used to modify the $\alpha\left(\lambda_{1}\right)$ of the reference action spectrum, to simulate spectra with random measurement errors. A maximum error of $20 \%$ was considered to be appropriate based on the analysis of Platt et al. (1977), who showed the standard error of the mean of $\alpha^{B}$, for both algal cultures and natural phytoplankton populations, to be about $18 \%$.

Some 50 action spectra were produced in this manner, and used to calculate primary production as a function of depth, $P(z)$ (Eq. 8), computed for sun at the zenith using the atmospheric transmission model of Bird (1984) as implemented by Sathyendranath \& Platt (1988). For simplicity, the action spectrum, $P_{m}^{B}$ and chl a concentration were kept constant with depth. The calculation was repeated using a range of chl a concentrations (between 0.01 and $10.0 \mathrm{mg} \mathrm{m}^{-3}$ ) to assess the sensitivity of errors in the computed production to changing biomass. Furthermore, calculations were repeated using the minimum and the maximum $P_{m}^{B}$ values encountered during the cruise, of about 1.0 and $12.0 \mathrm{mg} \mathrm{C} \mathrm{mg}^{-1} \mathrm{chl} \mathrm{a} \mathrm{h}^{-1}$ respectively. The $P(z)$ values were integrated (trapezoid rule) over depth to give water-column primary production, $P_{Z,}$ for comparison with $P_{Z}$ computed using the reference action spectrum.

The errors in the realized $P_{z}$ values relative to the reference could be positive or negative. An average of the 50 relative errors for each chl a concentration was computed from absolute values of the errors, to avoid cancellation of signs. Table 2 shows the average and the range of relative errors for each chl a concentration for the maximum $P_{m}^{B}$ value. The errors increased with decreasing biomass. The average errors were lower for the minimum $P_{m}^{B}$ (the highest average error was less than $0.8 \%$ ) than for the maximum $P_{m}^{B}$. This may be explained as follows. Assume a euphotic zone divided into 2 layers separated by a saturation depth, $Z_{I_{k^{\prime}}}$ defined as the depth at which the irradiance $I$ is equal to $I_{k}\left(I_{k}=P_{m}^{B} / \alpha^{B}\right.$, the nominal irradiance at which light saturation sets in). Above $Z_{I_{k^{\prime}}}$ production is light-saturated and, thus, $P_{m}^{B}$ has a significant influence on $P(z)$ compared with $\alpha^{B}$. Below the saturation depth, however, production is light-limited. Therefore, $\alpha^{B}$ has a significant influence on $P(z)$ below the saturation depth. Thus, when $P_{m}^{B}$ is high, the light-saturation layer
Table 2 . Sensitivity analysis of errors in water-column primary production for a range of chl a concentrations $\left(\mathrm{mg} \mathrm{m}^{-3}\right)$; caused by random errors on the action spectrum of up to $\pm 20 \%$. The averages were computed using absolute values of 50 relative errors. The computations were carried out for noon irradiance and $P_{m}^{B}=12.0 \mathrm{mg} \mathrm{C} \mathrm{mg}^{-1} \mathrm{chl} \mathrm{a} \mathrm{h}^{-1}$

\begin{tabular}{|cccc|}
\hline $\begin{array}{c}\text { Biomass } \\
\text { Chl a }\end{array}$ & $\begin{array}{c}\text { Relative errors in primary production } \\
\text { \% }\end{array}$ \\
\hline 0.01 & 1.82 & 4.69 & 0.11 \\
0.05 & 1.79 & 4.66 & 0.04 \\
0.10 & 1.76 & 4.62 & 0.03 \\
0.20 & 1.70 & 4.51 & 0.07 \\
0.30 & 1.65 & 4.42 & 0.02 \\
0.40 & 1.61 & 4.32 & 0.00 \\
0.50 & 1.58 & 4.25 & 0.01 \\
0.60 & 1.55 & 4.19 & 0.01 \\
0.70 & 1.52 & 4.11 & 0.02 \\
0.80 & 1.51 & 4.04 & 0.02 \\
0.90 & 1.49 & 3.99 & 0.01 \\
1.00 & 1.48 & 3.94 & 0.03 \\
2.00 & 1.38 & 3.58 & 0.21 \\
3.00 & 1.33 & 3.37 & 0.10 \\
4.00 & 1.29 & 3.23 & 0.06 \\
5.00 & 1.27 & 3.12 & 0.03 \\
6.00 & 1.25 & 3.04 & 0.02 \\
7.00 & 1.24 & 2.98 & 0.00 \\
8.00 & 1.23 & 2.93 & 0.01 \\
9.00 & 1.22 & 2.89 & 0.01 \\
10.00 & 1.22 & 2.86 & 0.00 \\
& & & \\
\hline
\end{tabular}

will be less deep (shallow $Z_{I_{k}}$ ) than when $P_{m}^{B}$ is low. In such cases, the light-limited area of the euphotic zone would be a significant part of the total euphotic layer, and consequently errors in $\alpha^{B}$ would have a large effect on the integrated water-column primary production. The reverse would be true for a low $P_{m}^{B}$ value. Overall, the average errors did not exceed $1.8 \%$ for the entire range of biomass and the $2 P_{m}^{B}$ values tested.

\section{Sensitivity analysis of systematic errors}

To assess how water-column primary production is affected by systematic errors in the action spectrum, we again used the reference, simulated, action spectrum of Chaetoceros gracilis. The reference action spectrum was subjected to systematic errors of up to $\pm 20 \%$ in steps of $\pm 5 \%$. In other words, all the $12 \alpha\left(\lambda_{i}\right)$ of the spectrum were either increased or decreased by $5,10,15$ or $20 \%$, to generate a total of 8 action spectra, which differed systematically from the reference spectrum. Water-column primary production was computed using the different action spectra ( 1 reference and 8 subjected to systematic errors). The computation was done using

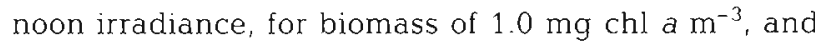
the maximum $P_{m}^{B}$ of $12.0 \mathrm{mg} \mathrm{C} \mathrm{mg}^{-1} \mathrm{chl} \mathrm{a} \mathrm{h}^{-1}$. 
Table 3. Systematic errors on the action spectrum: effect on water-column primary production (mg C m ${ }^{2} \mathrm{~h}^{-1}$ ). The computations were carried out for noon irradiance, biomass of $1.0 \mathrm{mg} \mathrm{chl} \mathrm{a} \mathrm{m}^{-3}$, and $P_{m}^{B}$ of $12.0 \mathrm{mg} \mathrm{C} \mathrm{mg}^{-1} \mathrm{chl} \mathrm{a} \mathrm{h}^{-1}$ Negative errors indicate underestimation and vice versa

\begin{tabular}{|ccc|}
\hline $\begin{array}{c}\text { Incremental } \\
\text { errors }(\%)\end{array}$ & $\begin{array}{c}\text { Primary } \\
\text { production }\end{array}$ & $\begin{array}{c}\text { Relative errors in } \\
\text { primary production }(\%)\end{array}$ \\
\hline-20 & 194 & -10.95 \\
-15 & 201 & -8.22 \\
-10 & 207 & -5.48 \\
-5 & 213 & -2.74 \\
0 & 219 & 0.00 \\
+5 & 224 & +2.28 \\
+10 & 229 & +4.57 \\
+15 & 234 & +6.85 \\
+20 & 239 & +9.13 \\
\hline
\end{tabular}

The results of this computation are shown in Table 3. As expected, when $\alpha(\lambda$, values were systematically underestimated, the water-column primary production was also underestimated (negative relative errors), and vice versa. The errors in water-column primary production ranged from -10.95 to $9.13 \%$ (Table 3), with an average of (absolute values) $6.3 \%$. For comparison, random errors at the same biomass $(1.0 \mathrm{mg} \mathrm{chl}$ $a \mathrm{~m}^{-3}$ ) and $P_{m}^{B}$ value (12.0 $\mathrm{mg} \mathrm{C} \mathrm{mg}^{-1} \mathrm{chl} \mathrm{a} \mathrm{h}^{-1}$ ) ranged from 0 to $3.9 \%$, with an average of about $1.5 \%$ (Table 2 ). Therefore, the errors in water-column primary production caused by systematic errors in the action spectrum are higher than those caused by random errors in the spectrum.

\section{Daily water-column primary production: comparison with measured in situ production}

As in the last 2 sections, Eq. (8) (Sathyendranath \& Platt 1989) was used to compute primary production $P(z)$, using the measured action spectrum. Then, $P(z)$ was integrated over both depth and time, to get daily water-column primary production $P_{Z, T}$. These $P_{Z_{1}}$ values were then compared with the 7 in situ $P_{Z . T}$ values measured at the time-series location. The in situ $P_{Z \text {.T }}$ (at Stns 12 to 15 and 18 to 20) ranged from 1 to $2.45 \mathrm{~g} \mathrm{C}$ $\mathrm{m}^{-2} \mathrm{~d}^{-1}$, with a peak at Stn 18 (Table 4). The corresponding $P_{Z, T}$ computed using the measured action spectrum at the same stations showed a similar range (from 1.25 to $2.41 \mathrm{~g} \mathrm{C} \mathrm{m}^{-2} \mathrm{~d}^{-1}$ ).

In addition, similar data of Kyewalyanga et al. (1992, spectrally computed and in situ $P_{Z . T}$ ) from the Sargasso Sea, collected in April 1990, were included in the comparison. The in situ $P_{Z, T}$ values were used as benchmarks to test the performance of the spectrally resolved model. A linear regression analysis of the
Table 4. In situ daily water-column primary production $\left(P_{Z, T}\right.$ in situ) and daily water-column primary production $P_{z . r}\left(\mathrm{~g} \mathrm{C} \mathrm{m}^{-2}\right.$ $\left.\mathrm{d}^{-1}\right)$ computed using the measured $\left(P_{Z, T}\right.$ meas.) and the constructed $\left(P_{Z . T}\right.$ cons.) action spectra at each of the 20 stations sampled during the crusse. The percentage difference between the 2 computed $P_{Z, T}$ values is given in the last column

\begin{tabular}{|rccrr|}
\hline Stn & $P_{Z, r}$ in situ & $P_{Z, T}$ meas & $P_{Z, T}$ cons. & \multicolumn{1}{c}{$\%$} \\
\hline 2 & - & 0.460 & 0.488 & -6.2 \\
4 & - & 0.465 & 0.490 & -5.5 \\
7 & - & 0.364 & 0.375 & -3.0 \\
9 & - & 0.438 & 0.450 & -2.7 \\
12 & 1.067 & 1.250 & 1.250 & 0.0 \\
13 & 1.403 & 1.497 & 1.243 & 17.0 \\
14 & 1.397 & 1.163 & 1.103 & 5.2 \\
15 & 1.304 & 1.542 & 1.409 & 8.6 \\
17 & - & 1.140 & 1.107 & 10.8 \\
18 & 2.450 & 2.407 & 2.254 & 6.3 \\
19 & 1.939 & 2.158 & 2.117 & 1.9 \\
20 & 1.003 & 1.505 & 1.476 & 1.9 \\
22 & - & 0.519 & 0.519 & 0.0 \\
23 & - & 0.383 & 0.366 & 4.5 \\
25 & - & 0.240 & 0.275 & -14.4 \\
27 & - & 0.402 & 0.419 & -4.2 \\
28 & - & 0.238 & 0.283 & -18.6 \\
30 & - & 0.439 & 0.438 & 0.3 \\
31 & - & 1.165 & 0.952 & 18.3 \\
32 & - & 0.545 & 0.473 & 13.3 \\
\hline
\end{tabular}

computed $P_{Z, T}$ values on the in situ ones was performed $\left(r^{2}=0.91\right)$. Because the intercept was not significantly different from zero (at the 5\% level, Student's $t$-test), the analysis was repeated with the regression line forced through the origin. The slope of the line, $1.02 \pm 0.02$ (slope $\pm \mathrm{SE}$ ), not significantly different from 1.0 (at $p=0.05, n=14$ ), showed a good agreement between in situ and spectrally computed $P_{Z, T}$ (Fig. 10).

Further, the $\mathrm{r}^{2}$ value showed that $91 \%$ of the variation in the in situ $P_{Z, T}$ could be explained by the results of the spectrally resolved model. Although Fig. 10 shows only values greater than $0.8 \mathrm{~g} \mathrm{C} \mathrm{m}^{-2} \mathrm{~d}^{-1}$, the agreement between in situ and spectrally computed $P_{z, T}$ is known to hold for lower production values as well. Platt \& Sathyendranath (1988) have shown a nearly one-to-one relation for data collected from diverse environments (5 different regions sampled between 1983 and 1987 ), with $P_{Z, T}$ ranging from less than 0.1 to $2.5 \mathrm{~g} \mathrm{C} \mathrm{m}^{-2} \mathrm{~d}^{-1}$.

\section{Assignment of action spectra in computing $P_{Z, T}$ : comparison of results achieved using different approaches}

Since the computations of water-column primary production using the measured action spectrum were 


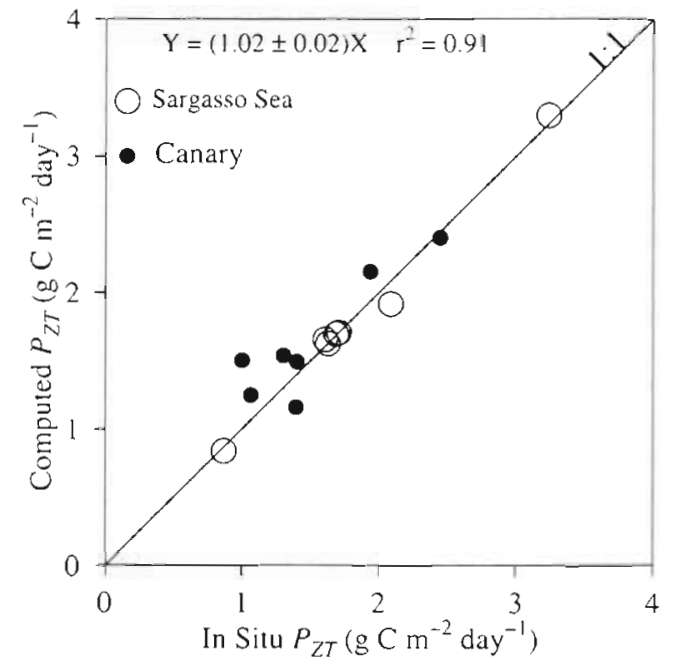

Fig. 10. Linear regression analysis of computed daily watercolumn primary production $P_{Z, T}$ on the in situ $P_{Z, T}$, for 14 stations. Data sampled on the time series location, this study; (O) data from Kyewalyanga et al. (1992), sampled from the Sargasso Sea in April 1990. The regression equation is $Y=$ $(1.02 \pm 0.02) X\left(r^{2}=0.91, n=14\right)$ with the slope not significantly different from 1.0 at the $5 \%$ significance level (the intercept was forced through the origin), indicating a good agreement between in situ and computed $P_{Z, T}$. The line is the 1:1 relation

seen to perform well, we used these computations as the standard against which other computations were evaluated. The other computations were the same as the standard calculations in all respects except in the assignment of action spectra. We examined 3 alternative assignments: (1) constructed action spectra corrected for the effects of non-photosynthetic pigments; (2) constructed action spectra uncorrected for nonphotosynthetic pigments; and (3) an invariant shape of the action spectrum throughout all the stations.

To compute $P_{Z, T}$ using a constant shape of the action spectrum for all the stations, an average spectrum of the 20 measured action spectra was determined (Fig. 4a), and this average shape was scaled to the magnitude of the broad-band $\alpha^{B}$ measured at each station. For comparison, $P_{Z, T}$ was also computed using the shape of the action spectrum presented in Sathyendranath et al. (1989, their Fig. 1), which is the commonly applied spectral shape (see also Platt \& Sathyendranath 1988, Platt et al. 1991, Sathyendranath et al 1995). This shape was also scaled to the magnitude of the broad-band $\alpha^{B}$ measured at each station. Daily water-column primary production at each of the 20 stations computed using each of the assignments of action spectra are plotted in Fig. 9 against station number.

The computed primary production using the measured action spectra [Fig, 9, $\left.P_{Z, T}(1)\right]$ ranged from 0.24 to $2.41 \mathrm{~g} \mathrm{C} \mathrm{m}^{-2} \mathrm{~d}^{-1}$ over the entire cruise (see also Table 4). The highest values were observed at the time series location, which was situated in the biomass-rich upwelling waters off the coast of Morocco (Stns 12 to 20). Also, Stn 31, located in the Labrador high-biomass waters, had higher $P_{Z, T}$ compared with the oligotrophic stations (Stns 2 to 9 and 22 to 30 ; Table 4, Fig. 9). The $P_{Z . T}$ computed using the 4 different assignments of action spectra showed similar variations along the stations, with notable differences only at 5 stations (the productive ones; Fig, 9). Overall, the difference between $P_{Z, T}$ calculated using the measured spectra and that calculated using the constructed action spectra (uncorrected) ranged from 0 to $18 \%$. A similar comparison, but with $P_{Z, T}$ calculated using the invariant spectral shape of $\alpha^{B}(\lambda)$ (the average of the spectra measured in this study) ranged from 0 to $17 \%$. The maximum error was only slightly higher $(19 \%)$ when the spectral shape reported in Sathyendranath et al. (1989) was used for all the stations.

To evaluate the effect of variation in just the shape of the action spectrum on the computed primary production, the $P_{Z, T}$ computed using the average shapes (the average computed here and that from Sathyendranath et al. 1989) can be compared with the $P_{Z . T}$ computed using the constructed action spectra (uncorrected), in which the spectral shapes were allowed to vary from station to station. The difference in $P_{Z, T}$ between the computations based on the average shape of the action spectrum presented here (Fig. 4a) and those based on the individual constructed action spectra ranged from -4.4 to $8.5 \%$. A similar comparison, but for $P_{Z, T}$ computed using the shape of the action spectrum from the literature (Sathyendranath et al. 1989) showed differences ranging from -1.4 to $18.2 \%$.

\section{DISCUSSION}

The procedure used to construct the action spectrum has the following advantages: to construct the action spectrum one needs only to measure the broad-band $\alpha^{B}$ and the phytoplankton absorption spectrum. Such measurements are much easier than the direct determination of the action spectrum. In narrow-band light determinations of the action spectrum (e.g. Lewis et al. 1985a, Warnock 1990, this study), the measurement, for some species, would be biased towards the absorption spectrum of PS II reaction center, because PS II is capable of transferring its excess excitation energy to PS I whereas PS I is not. That is to say, if a phytoplankton sample were illuminated by light of a wavelength absorbed by PS II pigments alone, some of the absorbed energy could be transferred to PS I, for use in photosynthesis. On the other hand, if the supplied light were of a wavelength absorbed by only PS I pigments, no energy could be transferred to PS II, leading to an 
imbalance in the operation of the photosystems, thereby affecting the overall photosynthetic efficiency. To avoid this bias, which might occur in narrow-band light measurements, Emerson (1957) suggested that enhancement background light, of wavelengths absorbed by PS II pigments, ought to be supplied (see Schofield et al. 1990, 1991, 1996). In the method developed here, these issues associated with narrow-wavelength determinations (without enhancement background light) are avoided by use of the broad-band $\alpha^{B}$ determined from polychromatic light (covering the range from 400 to $700 \mathrm{~nm}$ ) incubations in which the 2 photosystems (I and II) operate together. Furthermore, the shape of the absorption spectrum which is used in this method is influenced by all the photosynthetic pigments, regardless of whether they are associated with photosystem I or II.

We have seen from the sensitivity analysis how the constructed action spectrum could be affected by both random and systematic errors. The amplitude of the constructed action spectrum depends on the scaling factor, the broad-band $\alpha^{B}$. That is to say, a bias in $\alpha^{B}$ will be translated directly into errors in the magnitude of the constructed action spectrum. For example, the spectral quality of the tungsten-lamp irradiance (Fig. 5) in the broad-band incubator was shown to introduce a large bias, which, if ignored, could introduce a significant bias in the computed production.

Random and systematic errors on the action spectrum could also affect the computed water-column primary production. If the maximum possible error in $\alpha^{B}(\lambda)$ was set at $\pm 20 \%$, we found that the random errors would have relatively small effect (with the maximum error of about $4 \%$ ) on the computed production, whereas systematic ones would cause errors in the computed production of up to $11 \%$. This error might appear small, but it should be noted that the computation to assess systematic errors was carried out for noon irradiance; the errors could be higher for water-column primary production computed for early morning, late afternoon, or integrated over the day. This is because, at noon irradiance, production in a large part of the euphotic zone is light-saturated, with the consequence that $P_{m}^{B}$ exerts greater influence than $\alpha^{B}$ in the computed water-column production. In contrast, at low irradiance levels, production in the watercolumn is mostly light-limited, that is, $\alpha^{B}$ has a greater influence than $P_{m}^{B}$. In this case (of low irradiance) an error in $\alpha^{B}$ will result in large errors in the water-column production. For example, when the computations were repeated for a low irradiance $10 \%$ of the noon irradiance), given a $20 \%$ error in the action spectrum, there was nearly a 2 -fold increase in relative errors (from 11 to $19 \%$ ) in the computed water-column production.
It would be interesting to know how comparable these errors are to the precision attained in measuring in situ primary production. Therriault \& Platt (1978) studied spatial and temporal variability of in situ production (and other biological, chemical and physical variables) throughout 1 yr in St. Margaret's Bay, Nova Scotia, Canada. These authors showed a coefficient of variation in in situ production replicates of about $10 \%$, on average. In comparison, the sensitivity analysis predicts that for a maximum of $20 \%$ error in the action spectrum, random errors would cause, on average, $1.5 \%$ error in the water-column production and systematic errors would cause about $6 \%$ error.

In cases where information on the measured action spectrum is scarce or lacking, a single shape of the action spectrum is commonly applied (for example, Platt \& Sathyendranath 1988, Sathyendranath et al. 1989, 1995, Platt et al. 1991, Kyewalyanga et al. 1992, Longhurst et al. 1995). In such applications, it is assumed that ignoring the variation in the shape of $\alpha^{B}(\lambda)$ would cause negligible errors in the computed watercolumn primary production. How valid is this assumption? Does the use of a constant (invariant) shape for the action spectrum introduce significant errors in the computed water-column production? These questions were addressed in this work. It is interesting to find that the use of an average shape of the action spectrum gave results comparable to those in which the shape was allowed to vary from station to station (the relative error was, on average, about $2 \%$, ranging from -4 to $8 \%$ ), confirming that the assumption is valid, at least for the North Atlantic. However, the spectral shape to be used should be representative of the region in question, otherwise higher errors could be introduced. For example, when another shape (Sathyendranath et al. 1989) was used for the action spectrum the relative errors increased slightly (range -1 to $18 \%$ ).

In the California Current System region, Sosik (1996) made a sensitivity analysis on the use of constant parameters for computing large (spatial) scale primary production, and reached a similar conclusion.

\section{CONCLUDING REMARKS}

We have developed and applied a method to construct the photosynthetic action spectrum of natural phytoplankton populations from the shape of the phytoplankton absorption spectrum and the measured broad-band $\alpha^{B}$ With this method, photosynthetic action spectra may be determined routinely at sea with high efficiency.

Comparison of the measured and the constructed action spectra showed good agreement, indicating that the constructed spectrum is a good proxy for the mea- 
sured action spectrum. Through a sensitivity analysis, we analysed the effect on water-column primary production, of random and systematic errors on $\alpha^{B}(\lambda)$, and also of the presence of non-photosynthetic pigments in the phytoplankton absorption spectrum. The results from the analysis suggest that, in computing watercolumn primary production, systematic errors in the action spectrum would cause larger errors than random errors or the presence of non-photosynthetic pigments. Thus, in computing water-column primary production, it is important to have good estimates of the magnitude of $\alpha^{B}$.

On the other hand, realistic variations in the shape of the action spectra are likely to have only a small effect on the computed primary production. However, even these errors can be decreased if one has reasonable estimates of the shape of the spectrum for a given locality. This conclusion is supported by our sensitivity analysis, and by the computations of primary production using an invariant shape for the action spectrum.

Acknowledgements. We thank Brian Irwin and Jeff Anning for helping with design and construction of the spectral incubator, and with the broad-band photosynthesis versus irradiance measurements; Kathy Dower for helping with light measurements during the cruise; Heidi Maass for help with the programming; and Heidi Sosik for providing us with her paper in advance of its publication. This manuscript benefited from constructive comments of Drs Glen Harrison, Bruce Johnson, Carl Boyd, Jon Grant and 3 anonymous reviewers. The work presented here was supported by the Office of Naval Research; the National Aeronautics and Space Administration; the Department of Fisheries and Oceans; and the Natural Sciences and Engineering Research Council through research grants to S.S. and T.P. This work was carried out as part of the Canadian contribution to the Joint Global Ocean Flux Study.

\section{LITERATURE CITED}

Babin M, Morel A, Gagnon R (1994) An incubator designed for extensive and sensitive measurements of phytoplankton photosynthetic parameters. Limnol Oceanogr 39 : $694-702$

Babin M, Therriault JC, Nieke B, Reuter R (1995) Relationship between the maximum quantum yield of carbon fixation and the minimum quantum yield of chlorophyll a in vivo fluorescence in the Gulf of St. Lawrence. Limnol Oceanogr 40:956-968

Bidigare RR, Schofield O, Prézelin BB (1989) Influence of zeaxanthin on quantum yield of photosynthesis of Synechococcus clone WH7803 (DC2). Mar Ecol Prog Ser 56 177-188

Bidigare RR, Smith RC, Baker KS, Marra J (1987) Oceanic primary production estimates from measurements of spectral irradiance and pigment concentrations. Global Biogeochem Cycles 1:171-186

Bird RE (1984) A simple, solar spectral model for directnormal and diffuse horizontal irradiance. Sol Energy 32 : $461-471$

Britton JR (1956) Calculus. Holt, Rinehart and Winston, New York
Cleveland JS, Perry MJ, Kiefer DA, Talbot MC (1989) Maximal quantum yield of photosynthesis in the northwestern Sargasso Sea. J Mar Res 47:869-886

Cleveland JS, Weidermann AD (1993) Quantifying absorption by aquatic particles: a multiple scattering correction for glass-fiber filters. Limnol Oceanogr 38:1321-1327

Demers S, Roy S, Gagnon R, Vignault C (1991) Rapid lightinduced changes in cell fluorescence and in xanthophyllcycle pigments of Alexandrium excavatum (Dinophyceae) and Thalassiosira pseudonana (Bacillariophyceae): a photoprotective mechanism. Mar Ecol Prog Ser 76:185-193

Demmig-Adams B, Adams WW (1992) Photoprotection and other responses of plants to high light stress. Annu Rev Plant Physiol 43:599-626

Dubinsky Z, Falkowski PG, Wyman K (1986) Light harvesting and utilization by phytoplankton. Plant Cell Physiol 27 $1335-1349$

Duysens LNM (1956) The flattening of the absorption spectrum of suspension, as compared to that of solutions. Biochem Biophys Acta 19:1-12

Emerson R (1957) Dependence of yield of photosynthesis in long-wave red and on wavelength and intensity of supplementary light. Science 123:746

Harrison WG, Platt T, Lewis MR (1985) The utility of light-saturation models for estimating marine primary productivity in the field: a comparison with conventional 'simulated' in situ methods. Can J Fish Aquat Sci 42:864-872

Head EJH, Horne EPW (1993) Pigment transformation and vertical flux in an area of convergence in the North Atlantic. Deep Sea Res 40:329-346

Herman AW, Mitchell MR, Young SW (1984) A continuous pump sampler for profiling copepods and chlorophyll in the upper oceanic layers. Deep Sea Res 31:439-450

Hoepffner N, Sathyendranath S (1991) Effect of pigment composition on absorption properties of phytoplankton. Mar Ecol Prog Ser 73:11-23

Hoepffner N, Sathyendranath S (1992) Bio-optical characteristics of coastal waters: absorption spectra of phytoplankton and pigment distribution in the western North Atlantic. Limnol Oceanogr 37:1660-1679

Hoepffner N, Sathyendranath S (1993) Determination of the major groups of phytoplankton pigments from the absorption spectra of total particulate matter. J Geophys Res 98 $22789-22803$

Holm-Hansen O, Lorenzen CJ, Holmes RW, Strickland JDH (1965) Fluorometric determination of chlorophyll. J Cons Int Explor Mer 30:3-15

Hooker SB, Esaias WE, Feldman GC, Gregg WW, McClain CR (1992) An overview of SeaWiFS and ocean color SeaWiFS Technical Report Series, Vol 1, NASA, Greenbelt, MD

Irwin B, Anning J, Caverhill C, Platt $\Upsilon$ (1990) Primary production on the Labrador Shelf and in the Strait of Belle Isle in May 1988. Can Data Rep Fish Aquat Sci 784

Jeffrey SW (1981) An improved thin-layer chromatographic technique for marine phytoplankton pigments. Limnol Oceanogr 26:191-197

Johnsen G, Nelson NB, Jovine RVM, Prézelin BB (1994b) Chromoprotein- and pigment-dependent modeling of spectral light absorption in two dinoflagellates, Prorocentrum minimum and Heterocapsa pygmaea. Mar Ecol Prog Ser 114:245-258

Johnsen G, Sakshaug E (1993) Bio-optical characteristics and photoadaptive responses in the tox.c and bloom-forming dinoflagellates Gyrodinium aureolum, Gymnodinium galatheanum, and two strains of Prorocentrum minimum. J Phycol 29:627--642 
Johnsen G, Sakshaug E. Vernet M (1992) Pigment composition, spectral characterization and photosynthetic parameters in Chrysochromulina polylepis. Mar Ecol Prog Ser 83: $241-249$

Johnsen G, Samset O, Granskog L, Sakshaug E (1994a) In vivo absorption characteristics in 10 classes of bloomforming phytoplankton: taxonomic characteristics and responses to photoadaptation by means of discriminant and HPLC analysis. Mar Ecol Prog Ser 105:149-157

Kiefer DA, SooHoo JB (1982) Spectral absorption by manne particles of coastal waters of Baja California. Limnol Oceanogr 27:492-499

Kiefer D. Strickland JDH (1970) A comparative study of photosynthesis in seawater samples incubated under two types of light attenuator. Limnol Oceanogr 15:408-412

Kingslake R (1965) Applied optics and optical engineering. I. Light: its generation and modification. Academic Press Inc, New York

Kishino M, Takahashi M, Okami N, Ichimura S (1985) Estimation of the spectral absorption coefficients of phytoplankton in the sea. Bull Mar Sci 37:634-642

Krinsky NI (1979) Carotenoid pigments: multiple mechanisms for coping with the stress of photosensitized oxidations. In: Platt T, Li WKW (eds) Photosynthetic picoplankton. Can Bull Fish Aquat Sci 214:235-250

Kyewalyanga M, Platt T, Sathyendranath S (1992) Ocean primary production calculated by spectral and broad-band models. Mar Ecol Prog Ser 85:171-185

Lewis MR, Ulloa O, Platt T (1988) Photosynthetic action, absorption, and quantum yield spectra for a natural population of Oscillatoria in the North Atlantic. Limnol Oceanogr 33(1):92-98

Lewis MR, Warnock RE, Irwin B, Platt T (1985a) Measuring photosynthetic action spectra of natural phytoplankton populations. J Phycol 21:310-315

Lewis MR, Warnock RE, Platt T (1985b) Absorption and photosynthetic action spectra for natural phytoplankton populations: implications for production in the open ocean. Limnol Oceanogr 30(4):794-806

Lewis MR, Warnock RE, Platt T (1986) Photosynthetic response of marine picoplankton at low photon flux. In: Platt T, Li WKW (eds) Photosynthetic picoplankton. Can Bull Fish Aquat Sci 214:235-250

Longhurst A, Sathyendranath S, Platt T, Caverhill C (1995) An estimate of global primary production in the ocean from satellite radiometer data. J Plankton Res 17:1245-1271

Mantoura RFC, Llewellyn CA (1983) The rapid determination of algal chlorophyll and carotenoid pigments and their breakdown products in natural waters by reverse-phase high-performance liquid chromatography. Analyt Chım Acta 151:297-314

Mitchell BG, Kiefer DA (1984) Determination of absorption and fluorescence excitation spectra for phytoplankton. In: Holm-Hansen O, Bolis L, Gilles R (eds) Marine phytoplankton and productivity. Springer-Verlag, Berlin, $p$ $157-169$

Neori A, Vernet M. Holm-Hansen O, Haxo FT (1986) Relationship between action spectra for chlorophyll-a fluorescence and photosynthetic $\mathrm{O}_{2}$ evolution in algae. J Plankton Res 8:537-548

Neori A, Vernet M. Holm-Hansen O, Haxo FT (1988) Comparison of chlorophyll far-red and red fluorescence excitation spectra with photosynthetic oxygen action spectra for photosystem II in algae. Mar Ecol Prog Ser 44:297-302

Pickett JM, Myers J (1966) Monochromatic light saturation curves for photosynthesis in Chlorella. J Plant Physiol 41 $90-98$
Platt T, Caverhill C, Sathyendranath S (1991) Basin-scale estimates of oceanic primary production by remote sensing: the North Atlantic. J Geophys Res 96:15147-15159

Platt T, Denman KL, Jassby AD (1977) Modeling the productıvity of phytoplankton. In: Goldberg ED (ed) The sea: ideas and observations on progress in the study of the seas. John Wiley, New York, p 807-856

Platt T, Gallegos CL, Harrison WG (1980) Photoinhibition of photosynthesis in natural assemblages of marine phytoplankton. J Mar Res 38:687-701

Platt T, Sathyendranath S (1988) Oceanic primary production: estimation by remote sensing at local and regional scales. Science 241:1613-1620

Platt T, Sathyendranath S, Caverhill CM, Lewis MR (1988) Ocean primary production and available light: further algorithms for remote sensing. Deep Sea Res 35:855-879

Sakshaug $E$, Johnsen G, Andresen K, Vernet M (1991) Modeling of light-dependent algal photosynthesis and growth: experiments with the Barents Sea diatoms Thalassiosira nordenskioeldii and Chaetoceros furcellatus. Deep Sea Res 38:415-430

Sathyendranath S, Longhurst A, Caverhill CM, Platt T (1995) Regionally and seasonally differentiated primary production in the North Atlantic. Deep Sea Res 42:1773-1802

Sathyendranath S, Platt $T$ (1988) The spectral irradiance field at the surface and in the interior of the ocean: a model for applications in oceanography and remote sensing. J Geophys Res 93:9270-9280

Sathyendranath S, Platt T (1989) Computation of aquatic primary production: extended formalism to include effects of angular and spectral distribution of light. Limnol Oceanogr 34:188-198

Sathyendranath S, Platt T, Caverhill CM, Warnock RE, Lewis MR (1989) Remote sensing of oceanic primary production: computations using a spectral model Deep Sea Res 36: $431-453$

Schofield O, Bidigare RR, Prézelin BB (1990) Spectral photosynthesis, quantum yield and blue-green light enhancement of productivity rates in the diatom Chaetoceros gracile and the prymnesiophyte Emiliania huxleyi. Mar Ecol Prog Ser 64:175-186

Schofield O, Prézelin BB, Johnsen G (1996) Wavelength dependency of the maximum quantum yield of carbon fixation for two red dinoflagellates, Heterocapsa pygmaea and Prorocentrum minimum (Pyrrophyta): implications for measuring photosynthetic rates. J Phycol 32:574-583

Schofield O, Prézelin BB, Smith RC, Stegmann PM, Nelson NB, Lewis MR, Baker KS (1991) Variability in spectral and nonspectral measurements of photosynthetic light utilization efficiencies. Mar Ecol Prog Ser 78:253-271

Siefermann-Harms D (1987) The light-harvesting and protective functions of carotenoids in photosynthetic membranes. Physiol Plant 69:561-568

Snedecor GW, Cochran WG (1989) Statistical methods. Iowa State Unıversity Press, Ames

Sosik HM (1996) Bio-optical modeling of primary production: consequences of variability in quantum yield and specific absorption. Mar Ecol Prog Ser 143:225-238

Sosik HM, Mitchell BG (1995) Light absorption by phytoplankton, photosynthetic pigments and detritus in the California Current System. Deep Sea Res 42:1717-1748

Strickland JDH, Parsons TJ (1972) A practical handbook of seawater analysis. Bull Fish Res Bd Can 167

Therriault JC, Platt T (1978) Spatial heterogeneity of phytoplankton and related factors in the near-surface waters of an exposed coastal embayment. Limnol Oceanogr 23: $888-899$ 
Vernon LP (1960) Spectrophotometric determination of chlorophylls and phaeophytins in plant extracts. Anal Chem 32:463-481

Warnock RE (1990) Photosynthetic characteristics of picoplankton and natural phytoplankton assemblages. $\mathrm{PhD}$ thesis, Dalhousie University, Halifax

Yentsch CS (1962) Measurement of visible light absorption by

This article was submitted to the editor particulate matter in the ocean. Limnol Oceanogr 7:207-217 Yentsch CS, Menzel DW (1963) A method for the determination of phytoplankton chlorophyll and phaeophytin by fluorescence. Deep Sea Res 10:221-231

Zscheile FP, Comar GL (1941) Influence of preparative procedure on the purity of chlorophyll components as shown by absorption spectra. Bot Gaz 102:463-481

Manuscript first received: July 15, 1996

Revised version accepted: November 25, 1996 